\title{
The Standard of Care in Type 2 Diabetes: Re-evaluating the Treatment Paradigm
}

\author{
Viswanathan Mohan - Mark E. Cooper - David R. Matthews • \\ Kamlesh Khunti
}

Received: December 13, 2018 / Published online: February 13, 2019

(C) The Author(s) 2019

\begin{abstract}
There is currently a worldwide epidemic of type 2 diabetes (T2D) that is predicted to increase substantially in the next few years. With $80 \%$ of the global T2D population living in low to middleincome countries, there are issues with cost and of access to appropriate medicines. The objective

This symposium took place on the 3rd of October 2018 as part of the 54th Annual Meeting of the European Association for the Study of Diabetes (EASD) in Berlin, Germany.
\end{abstract}

Chairperson: Viswanathan Mohan. Speakers: Mark E. Cooper, David R. Matthews and Kamlesh Khunti.

Enhanced Digital Features To view enhanced digital features for this article go to https://doi.org/10.6084/ m9.figshare.7611197.

V. Mohan $(\square)$

Madras Diabetes Research Foundation and Dr Mohan's Diabetes Specialities Centre, Chennai, India

e-mail: drmohans@diabetes.ind.in

M. E. Cooper

Central Clinical School, Monash University,

Melbourne, VIC, Australia

D. R. Matthews

Oxford Centre for Diabetes, Endocrinology and Metabolism, University of Oxford, and Harris

Manchester College, Oxford, UK

K. Khunti

Diabetes Research Centre, University of Leicester, Leicester, UK of this symposium was to provide an overview of the efficacy and safety of glucose-lowering drugs, focussing in particular on sulfonylureas (SUs) in patients with T2D using data taken from both randomised controlled trials (RCTs) and realworld studies, the application of strategies to ensure optimal patient adherence and clinical outcomes, and the optimal use of SUs in terms of dose adjustment and agent choice to ensure the best clinical outcome. The symposium began by exploring a profile of the typical patient seen in diabetes clinical practice and the appropriate management of such a patient in the real world, before moving on to an overview of the risks associated with T2D and how the currently available agents, including newer antidiabetic medications, mitigate or exacerbate those risks. The final presentation provided an overview of real-world studies, the gap between RCTs and the real world, and the use of available glucose-lowering agents in daily clinical practice. Clinical evidence was presented demonstrating that tight glucose control improved both microvascular and macrovascular outcomes, but that aggressive treatment in patients with a very high cardiovascular risk could lead to adverse outcomes. Real-world data suggest that older agents such as SUs and metformin are being used in a large proportion of patients with T2D with demonstrable effectiveness, indicating that they still have a place in modern T2D management. The symposium, while acknowledging the need for newer antidiabetic drugs in specific situations 
and patient groups, recommended the continuation of SUs and metformin as the primary oral antidiabetic agents in resource-constrained regions of the world.

Funding:Servier.

Keywords: Effectiveness; Low resource regions; Metformin; Randomised controlled trials; Realworld data; Sulfonylureas; Type 2 diabetes

\section{INTRODUCTION}

\section{Dr Viswanathan Mohan}

There is currently a global epidemic of diabetessomething that was predicted decades ago by epidemiologists, who observed substantial increases in the prevalence of type 2 diabetes (T2D) among populations of indigenous people who adopted Western lifestyles [1-5]. The same trend can be seen in India: in 1990 there was only one state where noncommunicable diseases (including T2D) resulted in more deaths than communicable diseases, while in 2016 more people died of noncommunicable diseases in all 31 states, and diabetes is at the forefront of this trend [6]. Lifestyle is what has driven this change, with decreases in physical activity coupled with increases in fast food consumption, portion sizes, overall calories, carbohydrate consumption, and the intake of sugar and fat, leading to marked increases in obesity and T2D [7-9].

Hotspots of diabetes in addition to India include the Middle East [10, 11] and China $[12,13]$. Indeed, the large populations of India and China mean that they contribute a substantial proportion of the world's diabetes population. Epidemiological projections predict that diabetes prevalence will more than double by 2030 , with the greatest increases occurring in developing countries, particularly in Asia and parts of the Middle East [14]. Given that most of those with diabetes live in the developing world [15], the cost of therapy is a major consideration. While advances in diabetes care are occurring at a fast pace, many of these advances are unaffordable in places like India and China, where many people live below the poverty line.
There is hence an urgent need to address the epidemic of T2D, both in developing countries and in the West. Applying the standard of care in T2D can be an important component of how we address this global challenge.

\section{Compliance with Ethics Guidelines}

This article does not contain any studies with human participants or animals performed by any of the authors.

\section{CHAMPIONING THE STANDARD OF CARE IN CLINICAL PRACTICE: INTERACTIVE CASE CHALLENGE}

\section{Professor Mark Cooper}

The details of a typical case seen in diabetes clinical practice are summarised in Table 1. When this patient presents to the specialist, he is told that within 6 months of his last examination his glycosylated haemoglobin (HbA1c) has increased from $6.4 \%$ to $8.2 \%$, meaning that he has gone from prediabetes to diabetes. He has also gained $7 \mathrm{lb}$, putting his body mass index into the obese range. The patient tells the

Table 1 Case presentation details

Patient characteristics and presentation details

55-year-old male

Divorced

Recently lost his job

Lives alone

Recently diagnosed with T2D

Five-year history of prediabetes, treated with diet and exercise initially, then with metformin

Metformin therapy initiated approximately 2 years earlier

Patient does not like taking pills; complains about having to take metformin twice daily in addition to his two once-daily antihypertensive medications

Is reluctant to see a specialist 
specialist that he was recently laid off from his job, and that he hates taking pills. He wants to manage his diabetes through diet and exercise, but the specialist does not want to wait for the diet and exercise to work. The patient says that he doesn't understand why things have to change, because he feels just as well as he did 5 years ago; the specialist points out that the patient's latest tests show declining renal function, and that he needs aggressive treatment.

In making decisions about the most appropriate way to manage this patient, several things should be considered: adherence may be an issue for him; his renal function is reduced; he does not have any diabetes-related symptoms, but he is at risk for cardiovascular disease and diabetic kidney disease; and his diabetes is progressing, since metformin is no longer controlling his glycaemia.

The specialist decides to add a SU to the patient's regimen, starting him on gliclazide modified release (MR). This SU is a good choice for this patient because it has been shown to confer a lower risk of hypoglycaemic events compared with other SUs [16-20] for similar reductions in HbA1c [16]. Gliclazide MR may be used safely in this patient with impaired renal function, [21] and at risk of cardiovascular disease [22]. Moreover, it's a once-daily medication, which is likely to increase adherence [23, 24]. Gliclazide MR has not been associated with substantial weight gain $[24,25]$, which might not be an issue for this patient, and the average HbA1c reduction with SUs is $\sim 1.5 \%$ [26]. The specialist explains to the patient that initially he'll be taking half a tablet per day (30 mg), and will eventually increase the dose to two $60 \mathrm{mg}$ tablets per day, if needed. The patient objects to the titration, but the specialist explains why starting at a lower dose is needed to mitigate potential side effects. They discuss hypoglycaemia symptoms, and the specialist asks the patient to be adherent to the medication regimen.

At the follow-up appointment, the patient tells the specialist that he has a new job. The specialist goes through the patient's most recent tests, which show that he has responded to the SU therapy and now has HbA1c of $7.2 \%$. His kidney function is stable. When asked about adherence, the patient admits to sometimes forgetting to take his medication in the morning, and then taking it at night; the specialists asks him not to do that, since it may increase the risk of hypoglycaemia $[27,28]$. The specialist still has some concerns about the patient's weight, and doesn't think that diet and exercise alone will fix that, so changes in the patient's regimen may be warranted.

When considering a change in regimen, there are aspects that should be considered: since T2D is progressive, we know that metformin plus an SU will not be enough for many patients; the patient is employed now, and thus likely to be more active; he is reasonably compliant with his medication, showing a behavioural improvement, so may be open to improving his diet and exercising more; his weight is still an issue, but the fact that he still sometimes forgets his medication and then takes it when he shouldn't means that hypoglycaemia is still a concern.

In summary, a scenario like the one presented is very common in diabetes clinical practice. SUs are drugs of choice to be used with metformin due to their complementary modes of action [29]. These two drugs remain the most widely prescribed anti-hyperglycaemic agents worldwide [30], and have stood the test of time. Compared to other SUs, gliclazide has a lower risk of cardiovascular disease, a lower risk of hypoglycaemia and weight neutrality. In this particular case, gliclazide is a good choice as sodium glucose cotransporter 2 (SGLT2) inhibitors are generally contraindicated in patients with declining renal function, and DPP4 inhibitors are more expensive and so may not be affordable by many people in developing countries. Eventually one of the newer agents will have to be considered for a patient like this, but we at least know that agents with a long experience of use are effective in this setting.

\section{WHAT IS THE CLINICAL TRIAL EVIDENCE FOR REDUCING RISK?}

\section{Professor David Matthews}

The excess risks in T2D include death, myocardial infarction/angina, stroke, renal disease and 
end-stage renal disease (ESRD), retinopathy, neuropathy and heart failure. The mediators of these risks include non-modifiable factors such as age, sex, race and genetics, and modifiable factors such as hyperglycaemia, hypertension, hypoglycaemia, dyslipidaemia, smoking and obesity. Hyperglycaemia is a major risk factor, and there is good epidemiological data, such as National Health and Nutrition Examination Survey data, showing that the presence of hyperglycaemia decreases survival [31]. Mortality data from the UK Prospective Diabetes Study (UKPDS) showed that cardiac death, sudden death and stroke were responsible for $56 \%$ of deaths; these deaths could all be considered diabetes related, and are therefore to some extent modifiable [32].

\section{Intensive Glucose Control}

In terms of modifying risk, the UKPDS has also demonstrated that tight control of blood pressure and glucose leads to the greatest reduction in risk of any diabetes-related endpoint [33], including microvascular endpoints [34]. Overall, the intensive glucose policy employed by the UKPDS, which maintained HbA1c at a median of $7 \%$ over a follow-up of 10 years from T2D diagnosis, decreased the risk of any diabetes-related endpoint by $12 \%(p=0.029)$ [35]. The risk of myocardial infarction was reduced by $16 \%$ (borderline significance $p=0.052$ ), while the risk of microvascular endpoints was decreased by $25 \%$ ( $p=0.0099$ ) [35]. Subsequent clinical trials that have employed an intensive glucose control strategy include the Action in Diabetes and Vascular Disease: Preterax and Diamicron Modified Release Controlled Evaluation (ADVANCE) and the Action to Control CardiOvascular Risk in Diabetes (ACCORD) trials. In ADVANCE, patients were 8 years from diagnosis in both intensive treatment and control groups, with $\sim 21 \%$ having a history of myocardial infarction or stroke; in this trial, target $\mathrm{HbA} 1 \mathrm{c}$ was $\leq 6.5 \%$ [36]. Over the 66-month follow-up, the differences in HbA1c between groups evolved slowly (Fig. 1), and while the difference was small, it was statistically significant. The effect of therapy on major

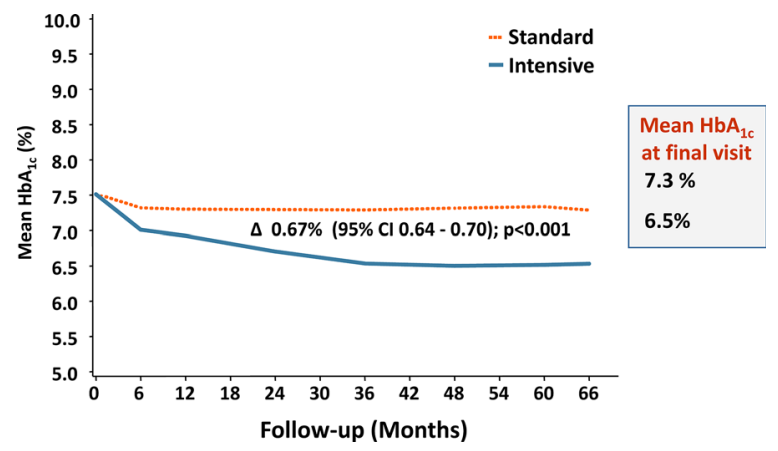

Fig. 1 Effects of standard and intensive therapy on HbAlc in ADVANCE [36] Figure adapted with permission from the Advance Collaborative Group, A. Patel, S. MacMahon, et al. Intensive blood glucose control and vascular outcomes in patients with type 2 diabetes. $\mathrm{N}$ Engl J Med. 2008;358:2560-72. [36]

microvascular events was significant, in favour of intensive therapy, with a relative risk reduction of $14 \% \quad(p=0.01)$; this reduction was mostly due to the effect on new or worsening nephropathy $(21 \% ; p=0.006)$, which is a positive signal in terms of ESRD and future risk of major events [36, 37]. Indeed, a subsequent analysis of renal outcomes, including ESRD, demonstrated that intensive glucose control resulted in a significant reduction in the risk of ESRD compared with standard therapy [38]. The ADVANCE Observational (ADVANCE-ON) study followed almost 8500 ADVANCE participants for a total follow-up time of 9.9 years, and found that reductions in the risk of ESRD persisted [39].

In the ACCORD study, the median duration of diabetes was 10 years, and one-third of patients had previous cardiovascular events while 5\% had congestive heart failure [40]. ACCORD had a very aggressive target HbA1c of $\leq 6.0 \%$, and the impact of this aggressive treatment was quick but negative. ACCORD was stopped early because of a $22 \%$ relative increase in mortality in the intensive therapy group versus the standard therapy group [40]. The patients in ACCORD had a high risk profile, higher than that for diabetes alone, but nevertheless the results of this trial showed that aggressive treatment of hyperglycaemia is not a safe strategy for many at-risk patient groups. 


\section{Impact of Treatment on Diabetes Complications}

Trials with some of the newer glucose-lowering medications have shown positive impacts on cardiovascular events. The Empagliflozin Cardiovascular Outcome Event Trial in Type 2 Diabetes Mellitus Patients-Removing Excess Glucose (EMPA-REG OUTCOME) trial of empagliflozin and the Liraglutide Effect and Action in Diabetes: Evaluation of Cardiovascular Outcome Results (LEADER) trial of liraglutide both demonstrated significant reductions in 3-point major adverse cardiovascular events and cardiovascular death with active treatment versus placebo [41, 42], while the Trial to Evaluate Cardiovascular and Other Long-term Outcomes With Semaglutide in Subjects With Type 2 Diabetes (SUSTAIN 6) trial of semaglutide also demonstrated a reduction in cardiovascular events [43]. Interestingly, post-trial monitoring of patients participating in the UKPDS has shown some long-term effects of glucose lowering; for example, the $25 \%$ reduction in microvascular disease seen at the end of the trial in the intensive therapy group was maintained in the 10-year follow-up, despite HbA1c having converged between the groups over time [44]. All-cause mortality was not significantly different between groups at the end of the trial (hazard ratio [HR] $0.94 ; p=0.44$ ), but by 10 years post-trial, there was a significant reduction in all-cause mortality in the intensive treatment group (HR 0.87; $p=0.006$ ) [44]. There were no such legacy effects seen with blood pressure, with any benefits seen at the end of the trial disappearing by the 10-year follow-up. Although the mechanism of these effects is still unknown, it is clear that poor glycaemic control in the past affects outcomes over many subsequent years.

\section{Impacts of Other Risk Factors on Risk in T2D}

Glycaemic control is not the only issue to be considered when treating patients with T2D. Hypoglycaemia is now regarded as a trigger for complications and pathology. It is known that different SUs cause different amounts of hypoglycaemia [20, 45], and from the ACCORD study we have seen that intensive therapy leads to more hypoglycaemic episodes, which required more assistance than standard therapy [40]. Hypoglycaemia is highly detrimental, and may have been a cause of the excess mortality seen in the ACCORD study [40]. Certainly, the risk of hypoglycaemia should be minimised.

Dyslipidaemia should always be treated, and most patients with T2DM should be on a statin [46]. A subanalysis of the ' $4 S^{\prime}$ ' study (Scandinavian Simvastatin Survival Study) showed that statin use in patients with T2D made a substantial difference in terms of decreasing cardiovascular events [47], suggesting that statin therapy is something that should be considered routine in patients with $\mathrm{T} 2 \mathrm{D}$.

Heart failure has been increasingly recognised as a serious complication in T2D [48]. Both the EMPA-REG and the Canagliflozin Cardiovascular Assessment Study (CANVAS) studies have demonstrated a positive impact of empagliflozin and canagliflozin on hospitalisation for heart failure, with empagliflozin demonstrating a $35 \%$ reduction versus placebo and canagliflozin demonstrating a 33\% reduction [41, 49].

In summary, we have good evidence from clinical trials for the glucose-lowering efficacy of metformin, SUs and other agents. There is evidence against aggressive late glucose reduction, while the clinical trials of SGLT2 inhibitors demonstrate protection against cardiovascular events and heart failure. The GLP1 receptor agonists liraglutide and semaglutide also have good evidence supporting their role in preventing cardiovascular disease. Ultimately, prevention of complications in T2D is complex, but the evidence has given us some simple rules that can be followed.

\section{REAL-WORLD DATA IN T2D: WHAT HAVE WE LEARNED ABOUT STANDARD-OF-CARE TREATMENT?}

\section{Professor Kamlesh Khunti}

There is a continuum of clinical research from RCTs to real-world observational trial evidence, moving from tightly controlled, homogeneous populations to broad populations such as those 


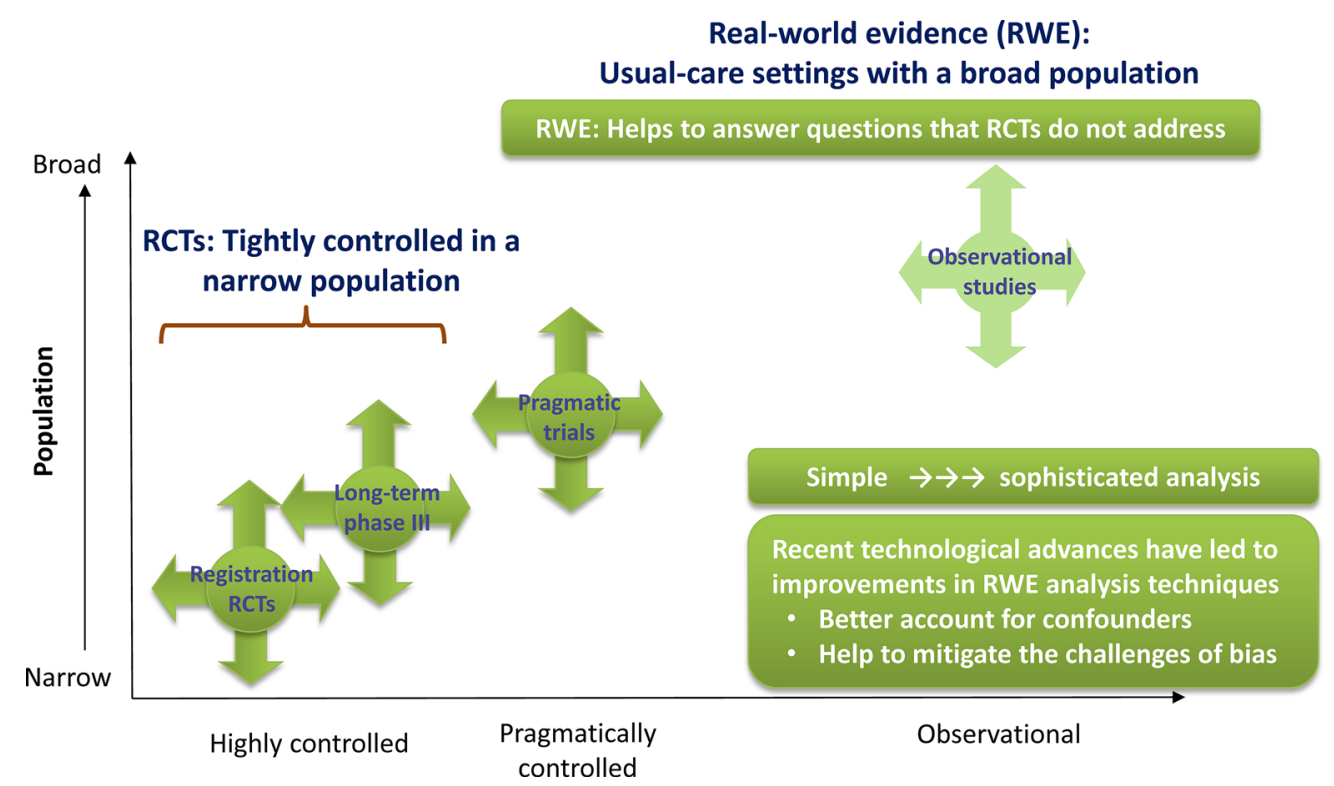

Fig. 2 The continuum of clinical research [54]. $R C T$ randomised controlled trial Adapted with permission from Saturni, S., F. Bellini, F. Braido, et al. Randomized

Controlled Trials and real life studies. Approaches and methodologies: a clinical point of view. Pulm Pharmacol Ther. 2014;27:129-38. [54]

seen in usual clinical practice (Fig. 2) [50]. RCTs can overcome potential issues with confounders that can be present in a broader population, while real-world studies help to answer some of the questions that RCTs may not have answered. The main differences in design between RCTs and real-world studies are summarised in Table 2 [51].

\section{The Gap Between RCTs and Real-World Evidence}

A meta-analysis that compared the effect of non-insulin antidiabetes drugs with placebo on change in HbA1c, body weight and overall hypoglycaemia from 27 RCTs found that the effect on HbA1c was similar across drug classes (reduction of $0.8-1.0 \%$ ), but the effects on weight and risk of hypoglycaemia varied [52]. The results from RCTs form the basis of standards of care, such as those from the American Diabetes Association [53], but often there is a difference between efficacy seen in RCTs and effectiveness in the real world. Reasons for this are generally because of differences in patient populations; RCTs are typically highly selective and often exclude patients aged 65 and older,

Table 2 Differences between randomised controlled trials and real-world studies

\begin{tabular}{|c|c|}
\hline $\begin{array}{l}\text { Randomised controlled } \\
\text { trials }\end{array}$ & Real-world studies \\
\hline $\begin{array}{l}\text { Quantifies efficacy of } \\
\text { drug }\end{array}$ & $\begin{array}{l}\text { Measures effectiveness of } \\
\text { therapy; includes health } \\
\text { outcomes and resource } \\
\text { utilization }\end{array}$ \\
\hline Interventional & Primarily observational \\
\hline $\begin{array}{l}\text { Comparison to gold } \\
\text { standard or placebo }\end{array}$ & $\begin{array}{l}\text { Comparison to standard } \\
\text { clinical practice }\end{array}$ \\
\hline Double blind/open label & Open label \\
\hline $\begin{array}{c}\text { Restrictive inclusion/ } \\
\text { exclusion criteria }\end{array}$ & $\begin{array}{l}\text { Broad inclusion/exclusion } \\
\text { criteria }\end{array}$ \\
\hline $\begin{array}{l}\text { Adherence encouraged } \\
\text { and monitored }\end{array}$ & Set in normal care setting \\
\hline Frequent study visits & No extra visits \\
\hline Drugs provided & $\begin{array}{l}\text { Drugs prescribed and collected } \\
\text { in normal way }\end{array}$ \\
\hline
\end{tabular}


those with comorbidities, and those taking other medications [54], while patients in daily practice are diverse and complex, likely to be older than 65 years, have several diseases and are likely to be taking multiple medications. Studies looking at how many real-world patients would be eligible for the landmark diabetes RCTs that have been conducted found that only $3.5-35.7 \%$ of patients in daily clinical practice would have been eligible for these studies (Fig. 3) [55, 56]. This makes translating RCT evidence into clinical practice very difficult.

Another reason why RCT results don't translate into the real world is therapeutic inertia [57]. Data show that intensification of insulin therapy is delayed by a median of 6 years despite patients having HbA1c levels > $7.5 \%$, and the same occurs with patients receiving oral antidiabetes agents, with delays of 6.0-7.1 years occurring for patients receiving one to three oral agents [58]. We have RCT evidence and guideline recommendations to support escalating therapy in a timely manner, but this is not something that happens in the real world. This inertia also occurs with patients receiving insulin therapy, with large variations between countries as to when basal insulin is initiated, and evidence that there is a failure to titrate therapy despite the fact that increasing the dose would have been appropriate [59-61]. Data show that the translation of RCT evidence is not happening in clinical practice irrespective of what medications are administered [62], and observational studies show that the management of patients has not changed substantially over the last 10 years.

\section{Efficacy and Durability}

A study of 10,256 patients with T2D from the UK and Germany receiving second-line therapies showed that mean HbA1c decreased by $\sim 1.1 \%$ regardless of the choice of secondline agent [63]. Patients who had treatment initiated within 6 months of their T2D diagnosis and patients who received second-line therapy in combination with metformin had greater reductions in HbA1c. SUs were a common choice for second-line therapy in this study [63]. Another retrospective study investigating the change in HbA1c levels over 18 months following initiation of second-line treatment also found that reductions in HbA1c were similar regardless of the second-line regimen used; this study also found that the mean time between the initiation of metformin therapy and initiating second-line therapy was 2.3 years,

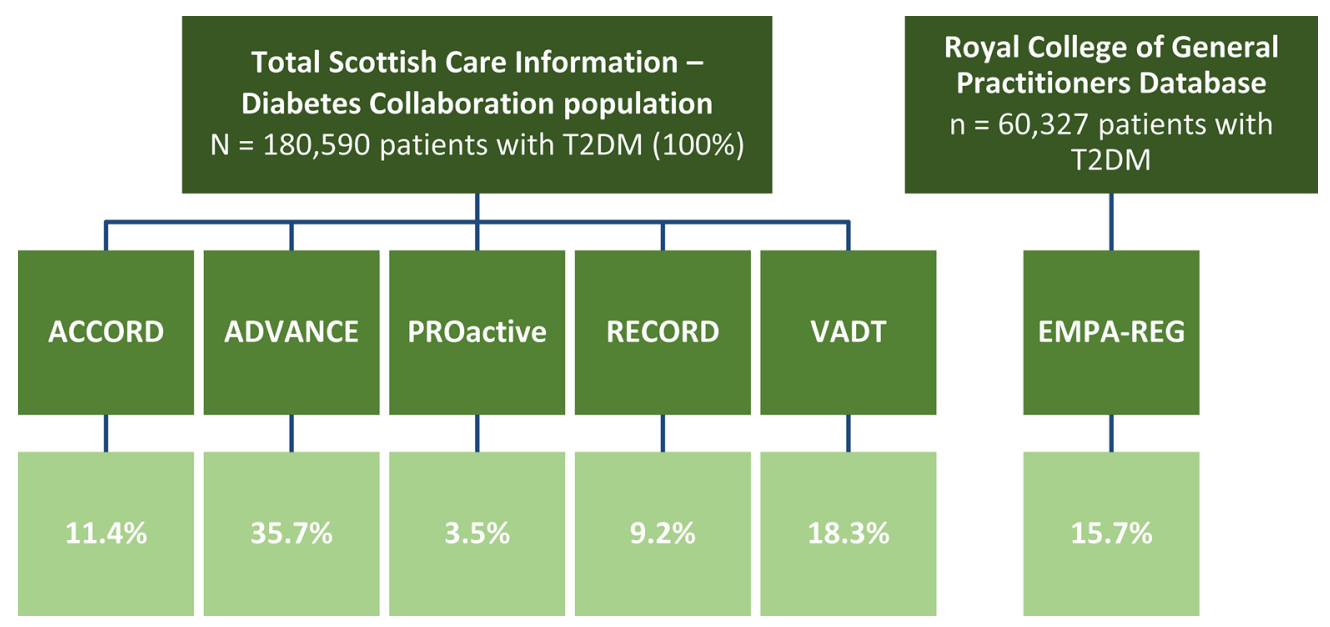

Fig. 3 Percent of real world patients eligible for Diabetes RCTs Adapted with permission from: Saunders, C., C.D. Byrne, B. Guthrie, et al. External validity of randomized controlled trials of glycaemic control and vascular disease: how representative are participants? Diabet Med.
2013;30:300-8. [56] and McGovern, A., M. Feher, N. Munro, and S. de Lusignan. Sodium-Glucose Co-transporter 2 (SGLT2) Inhibitor: Comparing Trial Data and Real-World Use. Diabetes Ther. 2017;8:365-76. [57] 
demonstrating once more the long delays between changes in therapy [64].

\section{Hypoglycaemia}

The UKPDS, ADVANCE, ACCORD, and the Veterans Affairs Diabetes Trial (VADT) studies of intensive glycaemic control all had increased rates of hypoglycaemia [35, 36, 40, 65]. In ADVANCE, the rates of severe hypoglycaemia were only slightly higher with intensive than with standard therapy (0.7 vs 0.4 events per 100 patients/year), mostly likely because of gradual and careful intensification of therapy over longer periods of time (Fig. 1) [36]. Bringing glycaemia down more quickly, such as what occurred in the ACCORD trial, was associated with an increased rate of hypoglycaemia (3.0 vs 1.0 events per 100 patients/year) [40].

Real-world evidence demonstrates that rates of hypoglycaemia are higher for insulin than for non-insulin therapies (insulin: 21\%; SUs and non-SU therapies: 5\%) [66]. Studies that have investigated rates of hypoglycaemia over the last 10 years according to age have shown that over the years there has been an increase in rates of hypoglycaemia, especially from the age of 50 years, which is surprising considering the availability of agents with a low risk of hypoglycaemia [67]. This suggests that these low-risk agents are not being used appropriately.

\section{Cardiovascular and Mortality Outcomes with SUs}

A network meta-analysis of 18 studies of 14,970 patients comparing more than two SUs looked at the mortality risk associated with the different SUs, with glibenclamide as the reference, and found that some SUs were associated with a higher risk and some with a lower risk [68]. A retrospective analysis of 11,141 patients with T2D did not find an increased mortality risk among the SUs, but their results did suggest that glimepiride may be better in patients with existing cardiovascular disease [69]. Another meta-analysis of second- and third-generation SUs that included 47 RCTs of $>52$ weeks' duration and a total of 37,650 patients found no increase in all-cause or cardiovascular mortality with SUs as a class, with no differences identified according to follow-up time or whether the SUs were administered as monotherapy or as an add-on to metformin [70].

\section{Practical Considerations}

With $80 \%$ of the people with T2D living in lowto middle-income countries, context-specific policies are required to improve access to essential medicines, including the use of generic products [71]. We know that even outside developing countries, the use of SUs, metformin and insulin is still high, and cost is an important consideration globally. The Discovering Treatment Reality of Type 2 Diabetes in RealWorld Settings (DISCOVER) study, which looked at diabetes-related data from 38 countries, showed that a large proportion of patients are receiving metformin, SUs, or metformin plus SUs as first-line therapy, and that many people are being given add-on SUs or metformin in the second line [72]. So a large proportion of the T2D population is still using these older therapies. The PURE study investigated access to therapy in 22 countries, and found that in some countries even metformin is not available, and many pharmacies are not holding insulin [73]. The World Health Organisation (WHO) recommends $\mathrm{SU}$ as an add-on therapy to metformin or $\mathrm{SU}$ alone in patients intolerant to metformin [74], which is a costeffective option for second-line therapy $[75,76]$.

In conclusion, well-designed real-world studies complement RCTs. We have extensive experience in using SUs over more than 60 years, and the risks and benefits of these agents are well understood. They have good efficacy and durability and a favourable cost/efficacy/safety ratio. Overall, therapies for T2D are initiated far too late, and we need to invest in holistic therapy for patients in a climate of limited resources.

\section{CONCLUDING REMARKS}

\section{Dr Viswanathan Mohan}

In clinical practice there are patients with T2D who have survived even for 50-60 years after their T2D diagnosis; for those patients, the only 
agents available to them when they were diagnosed were metformin and SUs [77]. Some of those patients are still taking this regimen, demonstrating the long-term efficacy of those older drugs. The WHO recommendations are very appropriate. It is too early to consider not using SUs and metformin because they still do have a place in therapy. Moreover, these drugs are perhaps the only ones affordable by the majority of patients in developing countries like India, where over $70 \%$ of patients pay 'out of pocket' for medicines [78]. The newer drugs are useful, particularly for specific indications or needs, such as a patient with cardiovascular risk, or a need for weight loss. So having more options for therapy is a positive thing.

\section{ACKNOWLEDGEMENTS}

Funding. The symposium and publication of this supplement was funded by Servier. The views and opinions expressed are those of the authors and not necessarily Servier.

Medical Writing Assistance. Writing assistance was provided by Sheridan Henness, PhD, on behalf of Springer Healthcare Communications. This assistance was funded by Servier.

Authorship. All named authors were involved in the conceptualization of the presentation at the Symposium and in writing and editing various drafts of the manuscript, and they meet the International Committee of Medical Journal Editors (ICMJE) criteria for authorship for this article, take responsibility for the integrity of the work as a whole, and have given their approval for this version to be published.

Disclosures. Doctor Mohan reports receiving consulting, honoraria or speaker fees and research or educational grants from Abbott, MSD, Novartis, Novo Nordisk, Eli Lilly, Lifescan J \& J, Sanofi Aventis, Roche Diagnostics, AstraZeneca, Servier, M/s USV Limited and Dr. Reddy's Laboratories. Professor Cooper reports consulting, honoraria or speaker fees from
AstraZeneca, Boehringer Ingelheim, Lilly, Merck, Novartis, Novo Nordisk, Sanofi and Servier. Professor Matthews reports consulting, honoraria, or speaker fees from Novo Nordisk, GlaxoSmithKline, Novartis, Eli Lilly, Sanofi Aventis, Janssen and Servier, and research support from Janssen. Professor Khunti reports consulting or speaker fees from Amgen, AstraZeneca, BMS, Boehringer Ingelheim, Janssen, Lilly, MSD, Novartis, Novo Nordisk, Roche, Sanofi and Servier, and research support from AstraZeneca, Boehringer Ingelheim, Lilly, MSD, Novartis, Janssen, Novo Nordisk, Roche and Sanofi.

Compliance with Ethics Guidelines. This article does not contain any studies with human participants or animals performed by any of the authors.

Open Access. This article is distributed under the terms of the Creative Commons Attribution-NonCommercial 4.0 International License (http://creativecommons.org/licenses/ by-nc/4.0/), which permits any noncommercial use, distribution, and reproduction in any medium, provided you give appropriate credit to the original author(s) and the source, provide a link to the Creative Commons license, and indicate if changes were made.

\section{REFERENCES}

1. Anjana RM, Deepa M, Pradeepa R, et al. Prevalence of diabetes and prediabetes in 15 states of India: results from the ICMR-INDIAB population-based cross-sectional study. Lancet Diabetes Endocrinol. 2017;5:585-96.

2. Bennett PH, Burch TA, Miller M. Diabetes mellitus in American (Pima) Indians. Lancet. 1971;2:125-8.

3. Herman WH, Zimmet P. Type 2 diabetes: an epidemic requiring global attention and urgent action. Diabetes Care. 2012;35:943-4.

4. India State-Level Disease Burden Initiative Collaborators. Nations within a nation: variations in epidemiological transition across the states of India, 1990-2016 in the Global Burden of Disease Study. Lancet. 2017;390:2437-60. 
5. West KM, Kalbfleisch JM. Influence of nutritional factors on prevalence of diabetes. Diabetes. 1971;20:99-108.

6. India State-Level Disease Burden Initiative Collaborators. The increasing burden of diabetes and variations among the states of India: the Global Burden of Disease Study 1990-2016. Lancet Glob Health. 2018;6:e1352-62.

7. Pradeepa R, Mohan V. Prevalence of type 2 diabetes and its complications in India and economic costs to the nation. Eur J Clin Nutr. 2017;71:816-24.

8. Ramachandran A, Snehalatha C, Shetty AS, Nanditha A. Trends in prevalence of diabetes in Asian countries. World J Diabetes. 2012;3:110-7.

9. Shrivastava U, Misra A, Mohan V, Unnikrishnan R, Bachani D. Obesity, diabetes and cardiovascular diseases in india: public health challenges. Curr Diabetes Rev. 2017;13:65-80.

10. Majeed A, El-Sayed AA, Khoja T, et al. Diabetes in the Middle-East and North Africa: an update. Diabetes Res Clin Pract. 2014;103:218-22.

11. Robert AA, Al Dawish MA, Braham R, Musallam MA, Al Hayek AA, Al Kahtany NH. Type 2 diabetes mellitus in Saudi Arabia: major challenges and possible solutions. Curr Diabetes Rev. 2017;13:59-64.

12. Li Y, Wang DD, Ley SH, et al. Time trends of dietary and lifestyle factors and their potential impact on diabetes burden in China. Diabetes Care. 2017;40:1685-94.

13. Lv J, Yu C, Guo Y, et al. Adherence to a healthy lifestyle and the risk of type 2 diabetes in Chinese adults. Int J Epidemiol. 2017;46:1410-20.

14. Wild S, Roglic G, Green A, Sicree R, King H. Global prevalence of diabetes: estimates for the year 2000 and projections for 2030. Diabetes Care. 2004;27:1047-53.

15. Guariguata L, Whiting DR, Hambleton I, et al. Global estimates of diabetes prevalence for 2013 and projections for 2035. Diabetes Res Clin Pract. 2014;103:137-49.

16. Andersen SE, Christensen M. Hypoglycaemia when adding sulphonylurea to metformin: a systematic review and network meta-analysis. Br J Clin Pharmacol. 2016;82:1291-302.

17. Chan SP, Colagiuri S. Systematic review and metaanalysis of the efficacy and hypoglycemic safety of gliclazide versus other insulinotropic agents. Diabetes Res Clin Pract. 2015;110:75-81.
18. Schopman JE, Simon AC, Hoefnagel SJ, et al. The incidence of mild and severe hypoglycaemia in patients with type 2 diabetes mellitus treated with sulfonylureas: a systematic review and meta-analysis. Diabetes Metab Res Rev. 2014;30:11-22.

19. Harrower A. Comparison of efficacy, secondary failure rate, and complications of sulfonylureas. J Diabetes Complications. 1994;8:201-3.

20. Schernthaner G, Grimaldi A, Di Mario U, et al. GUIDE study: double-blind comparison of oncedaily gliclazide MR and glimepiride in type 2 diabetic patients. Eur J Clin Invest. 2004;34:535-42.

21. Ioannidis I. Diabetes treatment in patients with renal disease: is the landscape clear enough? World J Diabetes. 2014;5:651.

22. Ferrannini E, DeFronzo RA. Impact of glucose-lowering drugs on cardiovascular disease in type 2 diabetes. Eur Heart J. 2015;36:2288-96.

23. Kardas P. The DIACOM study (effect of DosIng frequency of oral Antidiabetic agents on the COMpliance and biochemical control of type 2 diabetes). Diabetes Obes Metab. 2005;7:722-8.

24. Leiter LA, Shestakova MV, Trubitsyna NP, Piletič M, Satman I. Implementing an optimized glucoselowering strategy with a novel once daily modified release gliclazide formulation. Diabetes Res Clin Pract. 2016;112:50-6.

25. Leiter LA, Shestakova MV, Satman I. Effectiveness of gliclazide MR $60 \mathrm{mg}$ in the management of type 2 diabetes: analyses from the EASYDia trial. Diabetol Metab Syndr. 2018;10:30.

26. Nathan DM, Buse JB, Davidson MB, et al. Medical management of hyperglycemia in type 2 diabetes: a consensus algorithm for the initiation and adjustment of therapy: a consensus statement of the American Diabetes Association and the European Association for the Study of Diabetes. Diabetes Care. 2009;32:193-203.

27. Guillausseau P, Greb W. 24-hour glycemic profile in type 2 diabetic patients treated with gliclazide modified release once daily. Diabetes Metab. 2001;27:133-7.

28. Frey N, Laveille C, Paraire M, et al. Population PKPD modelling of the long-term hypoglycaemic effect of gliclazide given as a once-a-day modified release (MR) formulation. $\mathrm{Br} \mathrm{J}$ Clin Pharmacol. 2003;55:147-57.

29. Kalra S, Bahendeka S, Sahay R, et al. Consensus recommendations on sulfonylurea and sulfonylurea combinations in the management of type 2 
diabetes mellitus-International Task Force. Indian J Endocrinol Metab. 2018;22:132.

30. Lipska KJ, Yao X, Herrin J, et al. Trends in drug utilization, glycemic control, and rates of severe hypoglycemia, 2006-2013. Diabetes Care. 2017;40:468-75.

31. Gu K, Cowie CC, Harris MI. Mortality in adults with and without diabetes in a national cohort of the U.S. population, 1971-1993. Diabetes Care. 1998;21:1138-45.

32. Holman RR, Paul SK, Bethel MA, Neil HA, Matthews DR. Long-term follow-up after tight control of blood pressure in type 2 diabetes. N Engl J Med. 2008;359:1565-76.

33. Stratton IM, Cull CA, Adler AI, et al. Additive effects of glycaemia and blood pressure exposure on risk of complications in type 2 diabetes: a prospective observational study (UKPDS 75). Diabetologia. 2006;49:1761-9.

34. Stratton IM, Kohner EM, Aldington SJ, et al. UKPDS 50: risk factors for incidence and progression of retinopathy in type II diabetes over 6 years from diagnosis. Diabetologia. 2001;44:156-63.

35. UK Prospective Diabetes Study (UKPDS) Group. Intensive blood-glucose control with sulphonylureas or insulin compared with conventional treatment and risk of complications in patients with type 2 diabetes (UKPDS 33). Lancet. 1998;352:837-53.

36. ADVANCE Collaborative Group, Patel A, MacMahon S, Chalmers J, et al. Intensive blood glucose control and vascular outcomes in patients with type 2 diabetes. N Engl J Med. 2008;358:2560-72.

37. Zoungas S, de Galan BE, Ninomiya T, et al. Combined effects of routine blood pressure lowering and intensive glucose control on macrovascular and microvascular outcomes in patients with type 2 diabetes: new results from the ADVANCE trial. Diabetes Care. 2009;32:2068-74.

38. Perkovic V, Heerspink HL, Chalmers J, et al. Intensive glucose control improves kidney outcomes in patients with type 2 diabetes. Kidney Int. 2013;83:517-23.

39. Wong MG, Perkovic V, Chalmers J, et al. Long-term benefits of intensive glucose control for preventing end-stage kidney disease: ADVANCE-ON. Diabetes Care. 2016;39:694-700.

40. Action to Control Cardiovascular Risk in Diabetes Study Group, Gerstein HC, Miller ME, Byington RP, et al. Effects of intensive glucose lowering in type 2 diabetes. N Engl J Med. 2008;358:2545-59.
41. Zinman B, Wanner C, Lachin JM, et al. Empagliflozin, cardiovascular outcomes, and mortality in type 2 diabetes. N Engl J Med. 2015;373:2117-28.

42. Marso SP, Daniels GH, Brown-Frandsen K, et al. Liraglutide and cardiovascular outcomes in type 2 diabetes. N Engl J Med. 2016;375:311-22.

43. Marso SP, Bain SC, Consoli A, et al. Semaglutide and cardiovascular outcomes in patients with type 2 diabetes. N Engl J Med. 2016;375:1834-44.

44. Holman RR, Paul SK, Bethel MA, Matthews DR, Neil HA. 10-Year follow-up of intensive glucose control in type 2 diabetes. N Engl J Med. 2008;359:1577-89.

45. van Dalem J, Brouwers MC, Stehouwer CD, et al. Risk of hypoglycaemia in users of sulphonylureas compared with metformin in relation to renal function and sulphonylurea metabolite group: population based cohort study. BMJ. 2016;354:i3625.

46. American Diabetes Association. 9. Cardiovascular disease and risk management: standards of medical care in diabetes-2018. Diabetes Care. 2018;41:S86-S104.

47. Scandinavian Simvastatin Survival Study Group. Randomised trial of cholesterol lowering in 4444 patients with coronary heart disease: the Scandinavian Simvastatin Survival Study (4S). Lancet. 1994;344:1383-9.

48. Lehrke M, Marx N. Diabetes mellitus and heart failure. Am J Med. 2017;130:S40-50.

49. Neal B, Perkovic V, Mahaffey KW, et al. Canagliflozin and cardiovascular and renal events in type 2 diabetes. N Engl J Med. 2017;377:644-57.

50. Roche N, Reddel H, Martin R,, et al. Quality standards for real-world research. Focus on observational database studies of comparative effectiveness. Ann Am Thorac Soc. 2014;11(Suppl 2):S99-104.

51. Sherman RE, Anderson SA, Dal Pan GJ, et al. Realworld evidence-what is it and what can it tell us? N Engl J Med. 2016;375:2293-7.

52. Phung OJ, Scholle JM, Talwar M, Coleman CI. Effect of noninsulin antidiabetic drugs added to metformin therapy on glycemic control, weight gain, and hypoglycemia in type 2 diabetes. JAMA. 2010;303:1410-8.

53. American Diabetes Association. 8. Pharmacologic approaches to glycemic treatment: standards of medical care in diabetes-2018. Diabetes Care. 2018; 41:S73-S85. 
54. Saturni S, Bellini F, Braido F, et al. Randomized controlled trials and real life studies. Approaches and methodologies: a clinical point of view. Pulm Pharmacol Ther. 2014;27:129-38.

55. Saunders C, Byrne CD, Guthrie B, et al. External validity of randomized controlled trials of glycaemic control and vascular disease: how representative are participants? Diabet Med. 2013;30:300-8.

56. McGovern A, Feher M, Munro N, de Lusignan S. Sodium-glucose co-transporter 2 (SGLT2) inhibitor: comparing trial data and real-world use. Diabetes Ther. 2017;8:365-76.

57. Khunti K, Davies MJ. Clinical inertia-time to reappraise the terminology? Prim Care Diabetes. 2017;11:105-6.

58. Khunti K, Wolden ML, Thorsted BL, Andersen M, Davies MJ. Clinical inertia in people with type 2 diabetes: a retrospective cohort study of more than 80,000 people. Diabetes Care. 2013;36:3411-7.

59. Khunti K, Damci T, Meneghini L, et al. Study of Once Daily Levemir (SOLVE): insights into the timing of insulin initiation in people with poorly controlled type 2 diabetes in routine clinical practice. Diabetes Obes Metab. 2012;14:654-61.

60. Khunti K, Caputo S, Damci T, et al. The safety and efficacy of adding once-daily insulin detemir to oral hypoglycaemic agents in patients with type 2 diabetes in a clinical practice setting in 10 countries. Diabetes Obes Metab. 2012;14:1129-36.

61. Rosenstock J, Davies M, Home PD, et al. A randomised, 52-week, treat-to-target trial comparing insulin detemir with insulin glargine when administered as add-on to glucose-lowering drugs in insulin-naive people with type 2 diabetes. Diabetologia. 2008;51:408-16.

62. Khunti K, Gomes MB, Pocock S, et al. Therapeutic inertia in the treatment of hyperglycaemia in patients with type 2 diabetes: a systematic review. Diabetes Obes Metab. 2018;20:427-37.

63. Khunti K, Godec TR, Medina J, et al. Patterns of glycaemic control in patients with type 2 diabetes mellitus initiating second-line therapy after metformin monotherapy: retrospective data for 10256 individuals from the United Kingdom and Germany. Diabetes Obes Metab. 2018;20:389-99.

64. Wilding J, Godec $\mathrm{T}$, Khunti $\mathrm{K}$, et al. Changes in HbA1c and weight, and treatment persistence, over the 18 months following initiation of second-line therapy in patients with type 2 diabetes: results from the United Kingdom Clinical Practice Research Datalink. BMC Med. 2018;16:116.
65. Duckworth W, Abraira C, Moritz T, et al. Glucose control and vascular complications in veterans with type 2 diabetes. N Engl J Med. 2009;360:129-39.

66. Edridge CL, Dunkley AJ, Bodicoat DH, et al. Prevalence and incidence of hypoglycaemia in 532,542 people with type 2 diabetes on oral therapies and insulin: a systematic review and meta-analysis of population based studies. PLoS One. 2015;10:e0126427.

67. Zaccardi F, Davies MJ, Dhalwani NN, et al. Trends in hospital admissions for hypoglycaemia in England: a retrospective, observational study. Lancet Diabetes Endocrinol. 2016;4:677-85.

68. Simpson SH, Lee J, Choi S, et al. Mortality risk among sulfonylureas: a systematic review and network meta-analysis. Lancet Diabetes Endocrinol. $2015 ; 3: 43-51$.

69. Pantalone KM, Kattan MW, Yu C, et al. The risk of overall mortality in patients with type 2 diabetes receiving glipizide, glyburide, or glimepiride monotherapy: a retrospective analysis. Diabetes Care. 2010;33:1224-9.

70. Varvaki Rados D, Catani Pinto L, Reck Remonti L, Bauermann Leitão C, Gross JL. The association between sulfonylurea use and all-cause and cardiovascular mortality: a meta-analysis with trial sequential analysis of randomized clinical trials. PLoS Med. 2016;13:e1001992.

71. Mendis S, Fukino K, Cameron A, et al. The availability and affordability of selected essential medicines for chronic diseases in six low- and middle-income countries. Bull World Health Organ. 2007;85:279-88.

72. Nicolucci A, Arya N, Charbonnel B, et al. Treatment patterns and associated factors in 13,379 patients with type 2 diabetes initiating a second-line therapy: the DISCOVER study. In: 77th Scientific Sessions of the American Diabetes Association; 2017 June 9-13; San Diego, CA, USA.

73. Chow CK, Ramasundarahettige $\mathrm{C}, \mathrm{Hu} \mathrm{W}$, et al. Availability and affordability of essential medicines for diabetes across high-income, middle-income, and low-income countries: a prospective epidemiological study. Lancet Diabetes Endocrinol. 2018;6:798-808.

74. Roglic G, Norris SL. Medicines for treatment intensification in type 2 diabetes and type of insulin in type 1 and type 2 diabetes in low-resource settings: synopsis of the World Health Organization guidelines on second- and third-line medicines and type of insulin for the control of blood glucose levels in nonpregnant adults with diabetes mellitus. Ann Intern Med. 2018;169:394-7. 
75. Klarenbach S, Cameron C, Singh S, Ur E. Cost-effectiveness of second-line antihyperglycemic therapy in patients with type 2 diabetes mellitus inadequately controlled on metformin. CMAJ. 2011;183:E1213-20.

76. Zhang Y, McCoy RG, Mason JE, et al. Second-line agents for glycemic control for type 2 diabetes: are newer agents better? Diabetes Care. 2014;37:1338-45.
77. Mohan V, Shanthi Rani CS, Amutha A, et al. Clinical profile of long-term survivors and nonsurvivors with type 2 diabetes. Diabetes Care. 2013;36:2190-7.

78. Misra A, Sattar N, Tandon N, et al. Clinical management of type 2 diabetes in south Asia. Lancet Diabetes Endocrinol. 2018;6:979-91. 